\title{
Graphene Supported Pt/Ni Nanoparticles as Magnetically Separable Nanocatalysts
}

\author{
Ru Liu, Qingshan Zhao, Yang Li, Guoliang Zhang, Fengbao Zhang, and Xiaobin Fan
}

State Key Laboratory of Chemical Engineering, Key Laboratory for Green Chemical Technology, School of Chemical Engineering \& Technology, Tianjin University, Tianjin 300072, China

Correspondence should be addressed to Xiaobin Fan; xiaobinfan@tju.edu.cn

Received 12 March 2013; Accepted 10 September 2013

Academic Editor: Teng Li

Copyright (C) $2013 \mathrm{Ru}$ Liu et al. This is an open access article distributed under the Creative Commons Attribution License, which permits unrestricted use, distribution, and reproduction in any medium, provided the original work is properly cited.

Efficient recovery of nanocatalysts, especially the graphene supported noble metal catalysts, is a challenge. In this study, we report a simple one-step route to prepare the graphene supported $\mathrm{Pt} / \mathrm{Ni}$ nanocatalysts with ideal superparamagnetic properties. We demonstrated that they had excellent catalytic activities in the catalytic reduction of aromatic nitro compounds and could be easily separated from the reaction mixtures by applying an external magnetic field.

\section{Introduction}

Graphene [1], a one-atom-thick planar sheet of hexagonally arrayed $\mathrm{sp}^{2}$ carbon atoms, has attracted tremendous attention in recent years [2-5]. Especially, graphene has been emerging as a promising supporting in heterogeneous catalytic processes [6-10] due to its large surface areas [11], impressive mechanical strength $[12,13]$, chemical inertness, and strong interactions with metal clusters. In recent years, many monometallic and bimetallic catalytic nanoparticles, such as Pd [14], Au [15], Pt [16], Au@Pd [17], and Pt-on-Pd [18], have been successfully dispersed on graphene. The obtained hybrids show impressive catalytic performances in various reactions. However, most of the time, noble metals act as key components of these nanocatalysts, and the efficient recovery of these noble metals from reaction systems remains a challenge. In this respect, a promising solution to solve this problem is the magnetic separation by which the magnetically separable nanoparticles are employed to efficiently separate the catalyst from reaction mixture $[19,20]$. In fact, a number of functionalized magnetically separable nanoparticles have been employed in organic reactions as $\mathrm{C}-\mathrm{C}$ coupling [21], hydrogenation [22], oxidation [23], amination [24], and nitrile hydration [25].

Here, we report a one-step route to prepare the graphene supported Pt/Ni hybrids (Pt/Ni-G) (Scheme 1), which have superparamagnetic properties and show superior catalytic activities in the model reaction of p-nitrophenol (4-NP) reduction.

\section{Experimental}

2.1. Synthesis of Pt/Ni-G Hybrids. Graphite oxide was prepared by the modified Hummers method [26] and exfoliated into graphene oxide (GO) at a concentration of $0.5 \mathrm{mg} / \mathrm{mL}$ by sonication in water [27]. Typically, $100 \mathrm{~mL}$ of graphene oxide (GO) was dispersed in $50 \mathrm{~mL}$ Tannin (TA) aqueous solution $(5 \mathrm{mg} / \mathrm{mL})$ under sonication for $30 \mathrm{~min}$. Then, the excess TA was discarded by centrifugation and the as-prepared TAfunctionalized GO was dissolved into $50 \mathrm{~mL}$ of water. The concentrations of $\mathrm{H}_{2} \mathrm{PtCl}_{6}$ and $\mathrm{NiSO}_{4}$ were adjusted to $4.8 \times$ $10^{-4}$ and $1.2 \times 10^{-2} \mathrm{M}$ in the TA-GO solution, respectively; thus, Pt:Ni became 1:25. Nitrogen was purged through the solution for $5 \mathrm{~min}$, and then the solution was stirred in airtight conditions. After $30 \mathrm{~min}$ of stirring, $0.3 \mathrm{~mL}$ of $\mathrm{N}_{2} \mathrm{H}_{4} \cdot \mathrm{H}_{2} \mathrm{O}(80 \%)$ and $2 \mathrm{~mL}$ of $\mathrm{KOH}$ solution $(9.0 \mathrm{M})$ were injected into the solution. The solution turned black immediately and was kept stirred for $15 \mathrm{~min}$. Finally, the product was washed 8-10 times with ethanol and deionized water for purification purposes. 


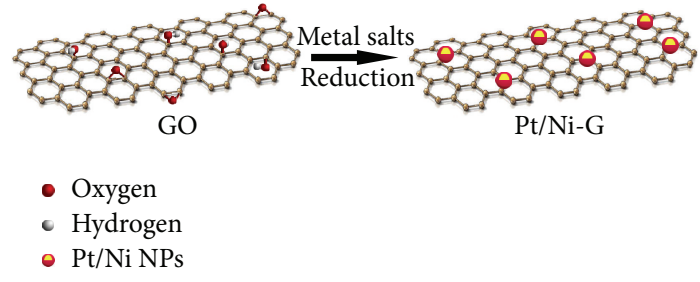

Scheme 1: Illustration of preparing Pt/Ni-G hybrids.

\subsection{Catalytic Reduction of p-Nitrophenol by Pt/Ni-G Hybrids.} To investigate the catalytic activity of the as-prepared hybrids, the reduction of p-nitrophenol (4-NP) was tested in a quartz cuvette. In brief, $20 \mu \mathrm{L}$ of $10^{-2} \mathrm{M}$ aqueous $4-\mathrm{NP}$ and $40 \mu \mathrm{L}$ of ultrasonically dispersed $\mathrm{Pt} / \mathrm{Ni}-\mathrm{G}$ solution $(0.1 \mathrm{mg} / \mathrm{mL})$ were introduced into $2 \mathrm{~mL}$ deionized water, resulting in a constant metal loading of $4.0 \mu \mathrm{g}$. Then, $0.3 \mathrm{~mL}$ of $10^{-1} \mathrm{M}$ aqueous $\mathrm{NaBH}_{4}$ was rapidly added. The yellow color of the solution gradually vanished, indicating the formation of $\mathrm{p}$-aminophenol (4-AP) [28]. The time-dependent UV-Vis absorption spectra were recorded in a scanning range of $200-600 \mathrm{~nm}$ at $25 \pm 1^{\circ} \mathrm{C}$.

2.3. Characterization. The as-prepared Pt/Ni-graphene hybrids were characterized by high-resolution transmission electron microscopy (HRTEM) (Philips Tecnai G2 F20), scanning electron microscopy (SEM) (Hitachi S-4800), energy dispersive X-ray spectroscopy (EDX) (Philips Tecnai G2 F20 \& Hitachi S-4800), and X-ray photoelectron spectroscopy (XPS) (PerkinElmer, PHI 1600 spectrometer). The X-ray diffraction (XRD) was conducted on a Bruker-Nonius D8 FOCUS diffractometer. The catalytic activity of Pt/Ni-G hybrids was measured by UV absorption spectra on a UV$2802 \mathrm{H}$ system with a temperature controller.

\section{Results and Discussion}

3.1. Synthesis of Pt/Ni-G Hybrids. The XRD diffraction pattern of the $\mathrm{Pt} / \mathrm{Ni}$-graphene hybrids was recorded to identify the product (Figure 1). The main diffraction peaks show the face-centered cubic (fcc) structure of both metallic nickel and nickel oxide [29]. Corresponding XPS pattern has authenticated this result. No peaks of Pt are observed because of the pretty low proportion of $\mathrm{Pt}: \mathrm{Ni}$, but the $2 \theta$ of $\mathrm{Ni}$ (111) peak shifts to a lower angle compared to that of nickel nanoparticles, indicating the alloy formation where the lattice expansion occurred due to the substitution of nickel atoms by larger platinum atoms [30]. Based on the $\mathrm{Ni}$ (111) peak, the crystallite size diameter $\left(D_{c}\right)$ of supported nanoparticles is calculated to be about $14.7 \mathrm{~nm}$ by Debye-Scherrer equation.

Further evidence for the chemical state and composition of the hybrids was obtained by X-ray photoelectron spectra (XPS). Compared with GO (Figure 2(a)), the full range XPS spectra of the obtained hybrids (Figure 2(b)) show an obvious decrease of $\mathrm{O}: \mathrm{C}$ atomic ratio. This result should be attributed to the partial removal of the oxide functional groups from GO during the reduction procedure (Figures $2(\mathrm{c})$ and $2(\mathrm{~d})$ ).

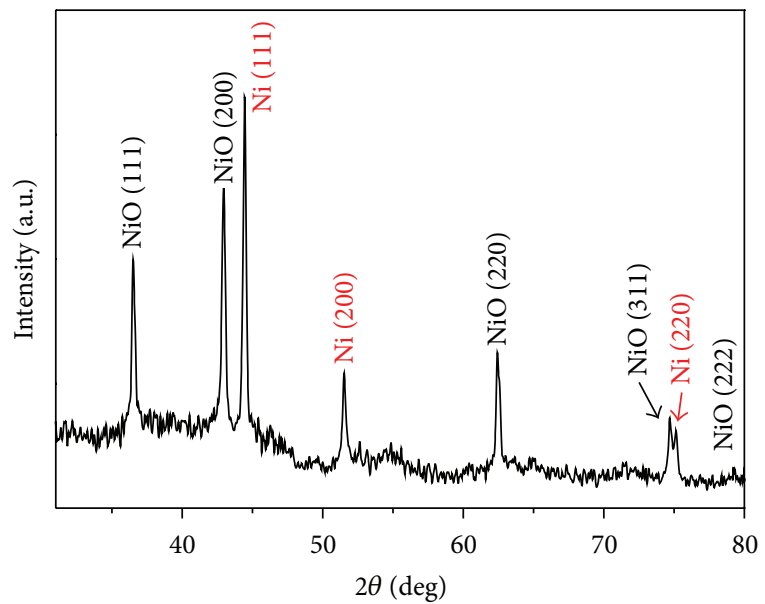

FIGURE 1: XRD pattern of the as-prepared Pt/Ni-G hybrids.

In addition, clear evidence for the existence of $\mathrm{Pt}$ and $\mathrm{Ni}$ in the hybrids is readily observed. The Pt $4 \mathrm{f}$ spectrum (Figure 2(e)) consists of two peaks for metallic platinum at $71.3\left(\mathrm{Pt} 4 \mathrm{f}_{7 / 2}\right)$ and $74.2 \mathrm{eV}\left(\mathrm{Pt} 4 \mathrm{f}_{5 / 2}\right)$, without the peaks for $\mathrm{Pt}^{2+}$ and $\mathrm{Pt}^{4+}$ at 72.8 and $74.6 \mathrm{eV}$, respectively [31]. This result indicates that $\mathrm{Pt}$ is present in the zero-valent metallic state in the alloy nanoparticles. In contrast, the $\mathrm{Ni} 2 \mathrm{p}_{3 / 2}$ spectrum (Figure $2(\mathrm{f})$ ) shows a complex structure with intense satellite signals of high binding energy adjacent to the main peaks, which may be ascribed to a multielectron excitation (shake-up peaks) [32]. After these shake-up peaks are considered, the Ni $2 \mathrm{p}_{3 / 2}$ spectrum has been deconvoluted into two peaks; the first small one located at $852.6 \mathrm{eV}$ corresponds to metallic nickel, and the main one located at 854.0 is assigned to $\mathrm{NiO}$ [33]. From the intensities of the deconvoluted XPS signal of Ni, it is obvious that the surface of the nanoparticles is predominately $\mathrm{NiO}$.

The surface morphological study was carried out by using TEM. As shown in Figure 3(a), spherical nanoparticles were homogeneously dispersed on the surfaces of graphene. The sizes of nanoparticles are in the range of $12-19 \mathrm{~nm}$, with a mean size of $15.4 \mathrm{~nm}$. This value is in close agreement with the diameter of $14.7 \mathrm{~nm}$ obtained from XRD.

Interestingly, it is easy to find that the graphene supported nanoparticles show a dark core and a comparatively pale shell under the HRTEM image of Pt/Ni-G (Figure 3(b)), indicating the core-shell structure. The lattice spacing in the core of the graphene supported Pt/Ni nanoparticles (marked as "a," Figure 3(b)) is $0.207 \mathrm{~nm}$, whereas those of pure $\mathrm{Pt}$ (111) and $\mathrm{Ni}$ (111) are 0.23 and $0.203 \mathrm{~nm}$, respectively. The supported $\mathrm{Pt} / \mathrm{Ni}$ nanoparticles also show $\mathrm{NiO}$ lattice fringes on the particle surface (marked as "b"), with the d-spacing of $0.24 \mathrm{~nm}$ corresponding to the $\mathrm{NiO}(200)$ planes $[34,35]$. These results suggest the alloy formation of $\mathrm{Pt}$ and $\mathrm{Ni}$, and the particles would be covered by a $\mathrm{NiO}$ layer that was formed by the surface oxidation.

These results are further supported by line scanning analysis. As shown in Figure 3(c), Pt is primarily in the $8 \mathrm{~nm}$ core while Ni uniformly is distributed on the whole surface of the $\mathrm{Pt} / \mathrm{Ni}$ nanoparticle. 


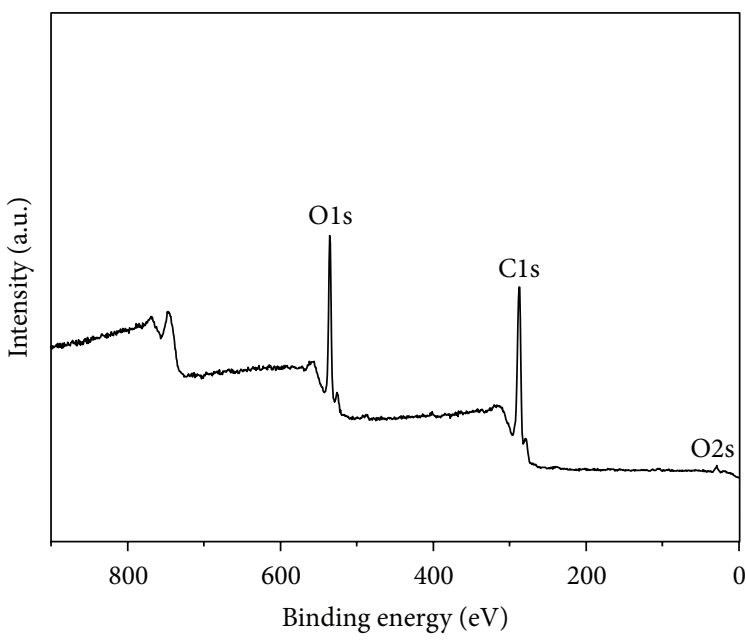

(a)

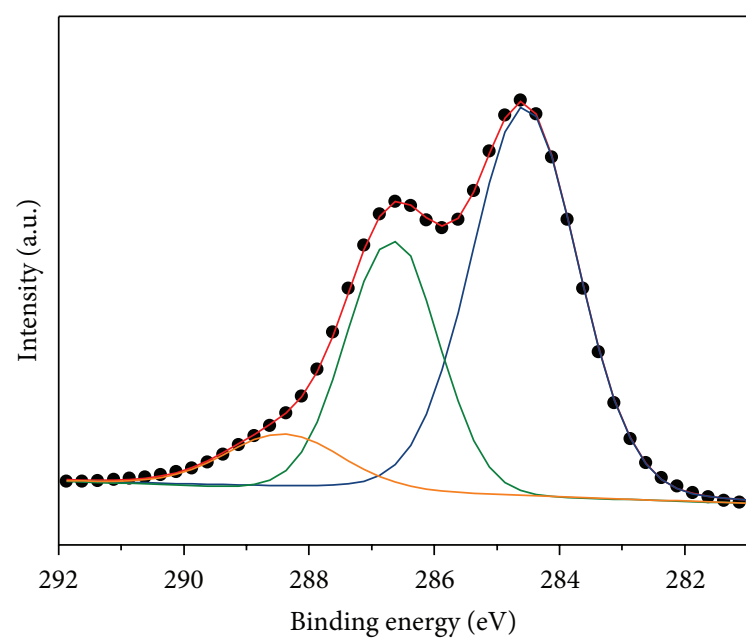

- Sum $-\mathrm{C}-\mathrm{O}-\mathrm{C}$ and $\mathrm{C}-\mathrm{OH}$

(c)

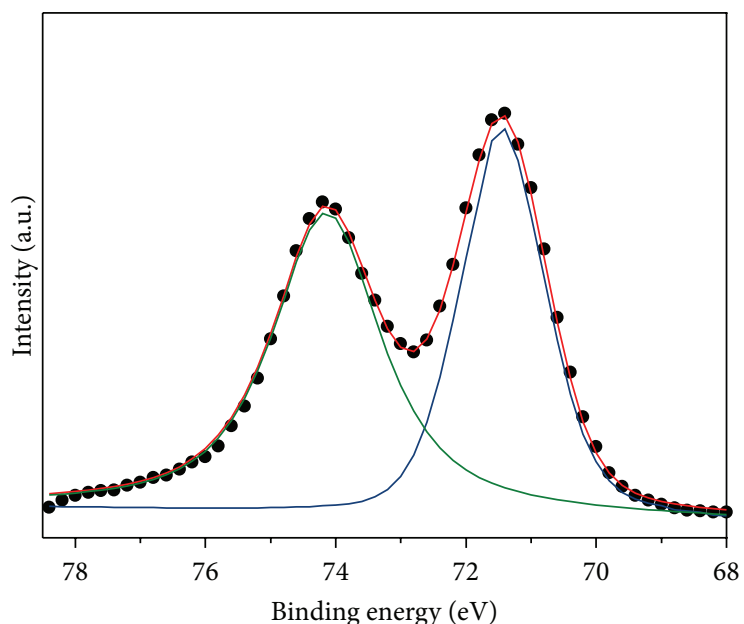

- Sum

- $\mathrm{Pt}(0) 4 \mathrm{f} 7$

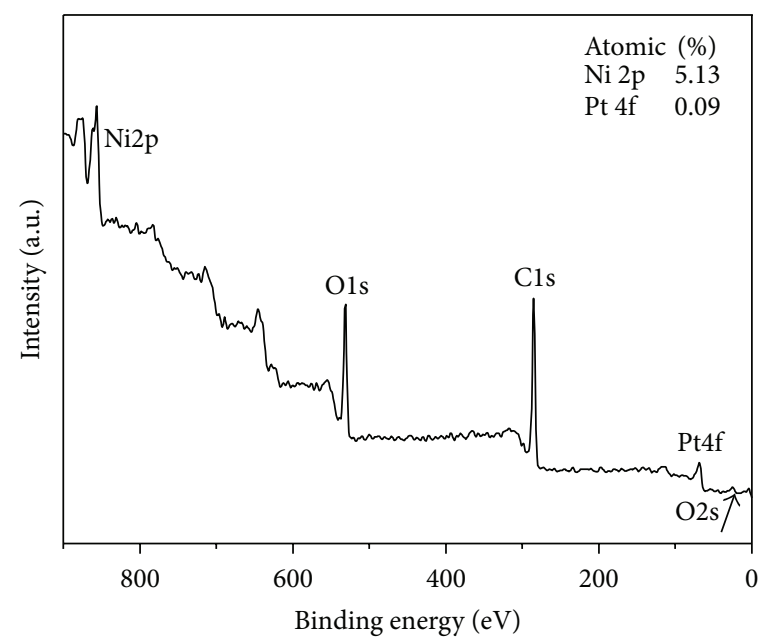

(b)

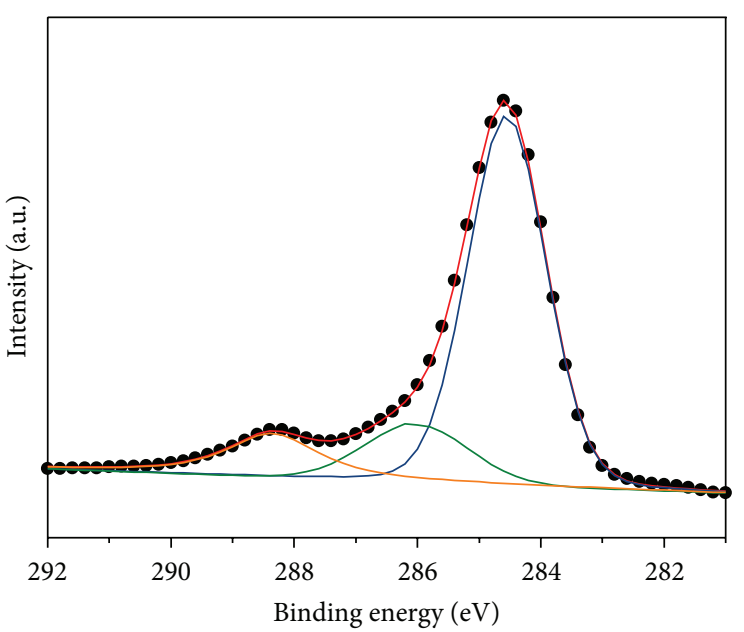

- Sum $\quad \mathrm{C}-\mathrm{O}-\mathrm{C}$ and $\mathrm{C}-\mathrm{OH}$

- C-C and C-H

- $\mathrm{O}-\mathrm{C}=\mathrm{O}$

(d)

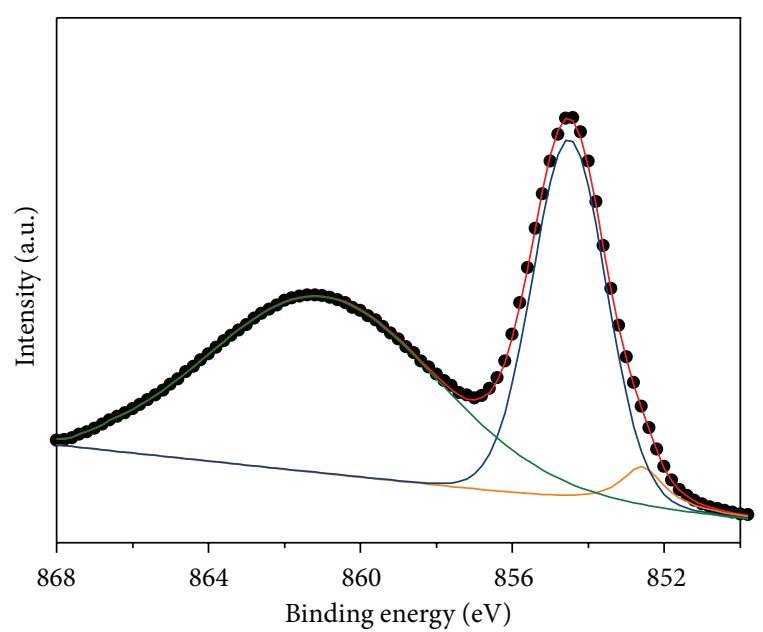

- Sum

- $\mathrm{NiO}$

_ Shake-up

(f)

Figure 2: Survey XPS spectra of GO (a) and Pt/Ni-G (b). Cls XPS spectra of GO (c) and Pt/Ni-G (d). Pt 4f spectra (e) and Ni 2p3 spectra (f) of Pt/Ni-G. 


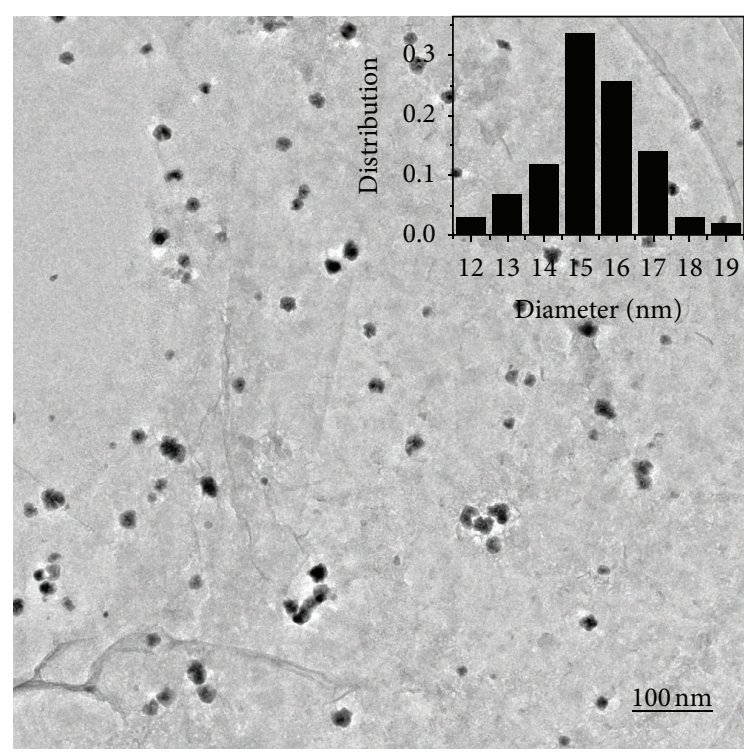

(a)

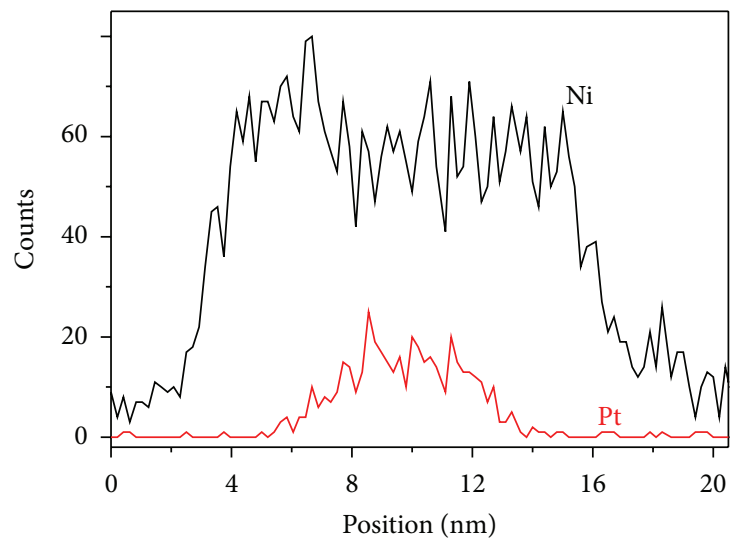

(c)

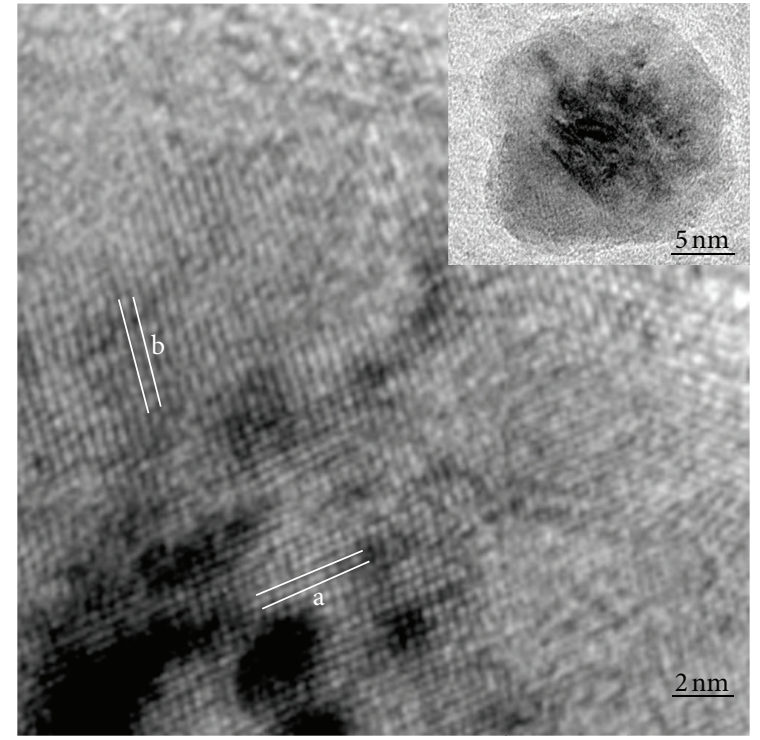

(b)

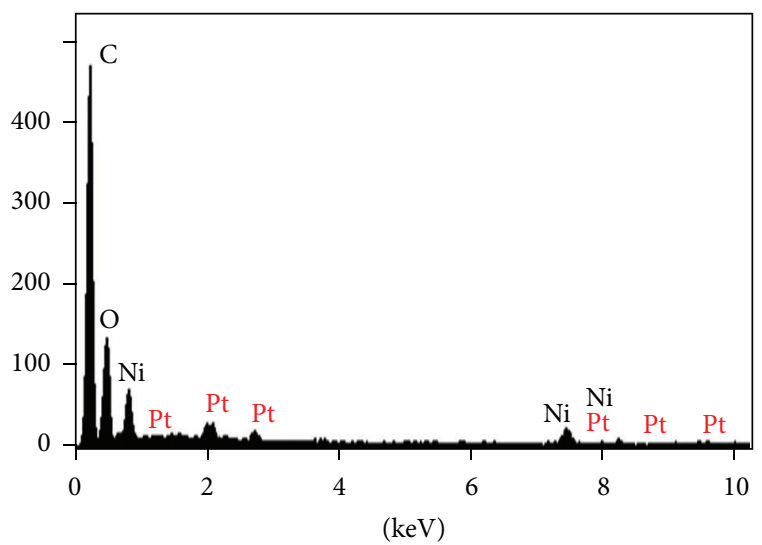

(d)

FIGURE 3: TEM image and size distribution (total no.: 101, mean diameter: $15.4 \mathrm{~nm}$ ) (a) and HRTEM image (b) of Pt/Ni-G bimetallic nanoparticles homogeneously decorated on the surface of graphene. Line scanning analysis (c) and corresponding EDX results (d).

Interestingly, quantitative analysis by EDX (Figure 3(d)) suggests that the $\mathrm{Pt}: \mathrm{Ni}$ atomic ratio is $1: 26$, a value close to the stoichiometric ratio $(1: 25)$ of the metal precursors. But the surface Pt: Ni atomic ratio measured by XPS is only 1:57 (Figure 2(b)). Given that XPS can only penetrate several nanometers of the surface, this result strongly supports the formation of a $\mathrm{NiO}$ layer out of the supported $\mathrm{Pt} / \mathrm{Ni}$ alloy. Quantitative energy dispersive X-ray spectroscopy (EDS) mapping confirms that both $\mathrm{Pt}$ and $\mathrm{Ni}$ are homogeneously distributed on the whole surface of graphene, shown in Figure 4 .

3.2. Magnetic Characterization. Figure 5(a) shows the magnetization versus field plots ( $M$ versus $H$ hysteresis loops) of Pt/Ni-G hybrids by Quantum Design SQUID-VSM magnetometer under -10 to $10 \mathrm{KOe}$ at room temperature. The saturation magnetization $\left(M_{s}\right)$ for the sample is $11.6 \mathrm{emu} / \mathrm{g}$. And the curve does not exhibit hysteresis, indicating that
$\mathrm{Pt} / \mathrm{Ni}$-G hybrids at room temperature show superparamagnetic behavior. Previous studies on magnetic nanoparticles have demonstrated that when the size of the magnetic particles decreases they change from multidomain to single domain [36]. Therefore, when particles become small enough (typically below $35 \mathrm{~nm}$ [37]), the magnetic moment in the domain fluctuates in direction, leading to superparamagnetism (SPM).

3.3. Catalytic Reaction. To probe the catalytic performances of the obtained hybrids, reduction of p-nitrophenol (4-NP) to its corresponding amino derivative was used as the model reaction. In brief, the catalytic reduction of 4-NP by excessive $\mathrm{NaBH}_{4}$ was carried out at room temperature under solvent free condition by using as-synthesized Pt/Ni-G hybrids catalysts. The reaction process was monitored by the UV-Vis spectrophotometry and conducted in the absence of catalysts first. It was observed that the yellow color of the solution deepened after the addition of $\mathrm{NaBH}_{4}$, and a red shift of the peak from 


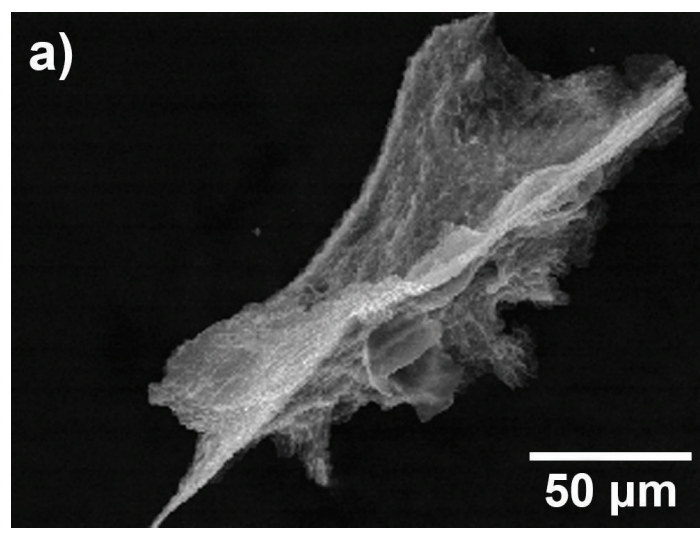

(a)

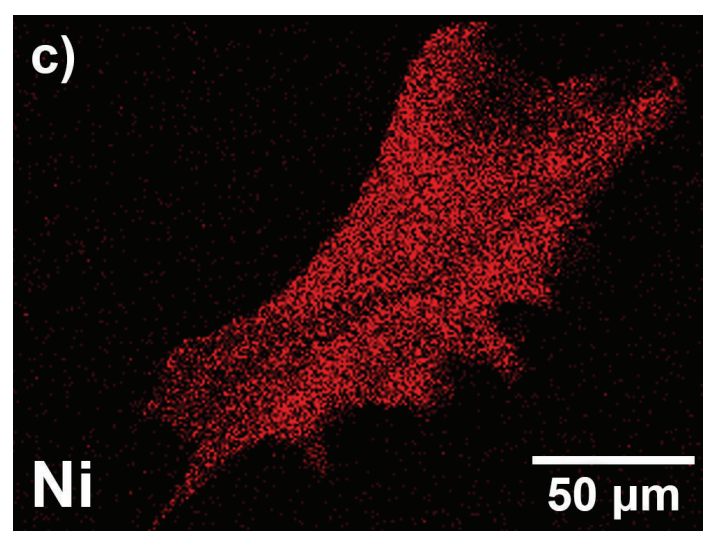

(c)

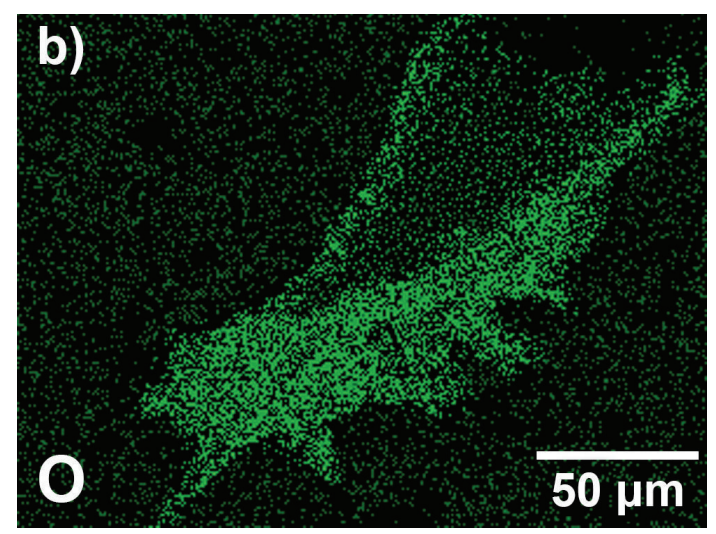

(b)

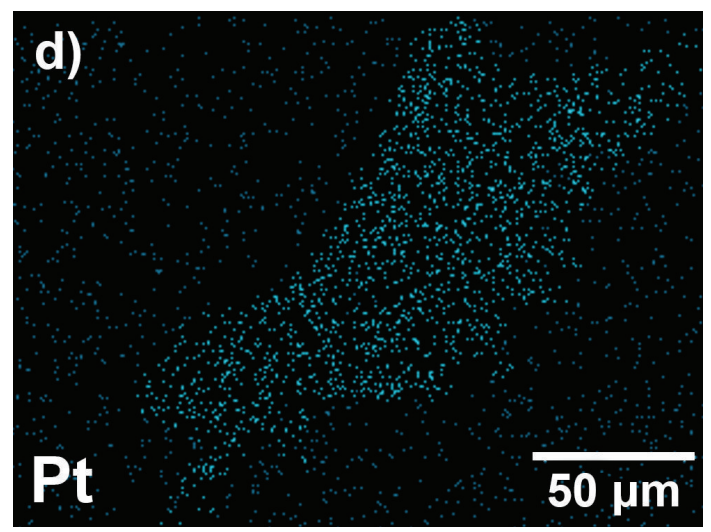

(d)

Figure 4: SEM image of Pt/Ni-G (a) and corresponding quantitative EDS element mapping of O (b), Ni (c), and Pt (d).

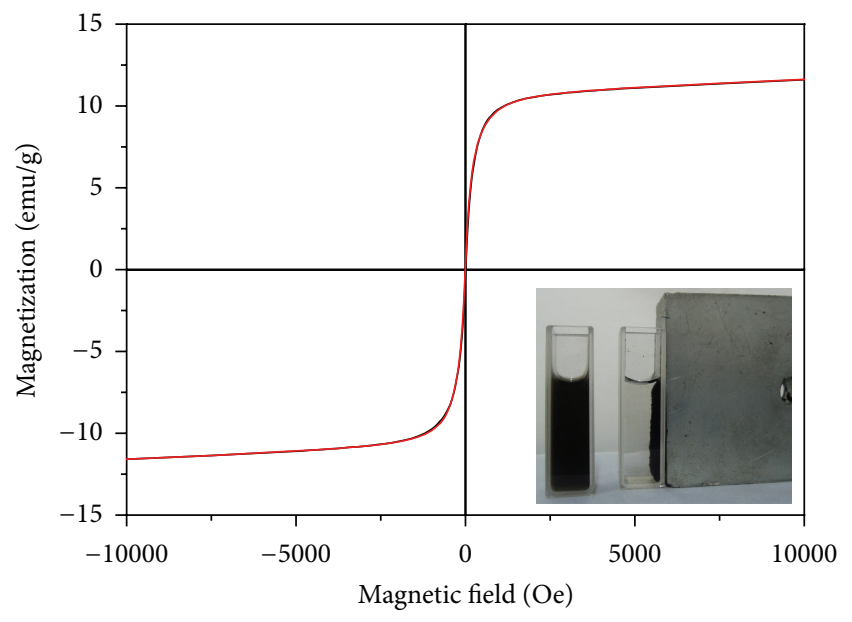

(a)

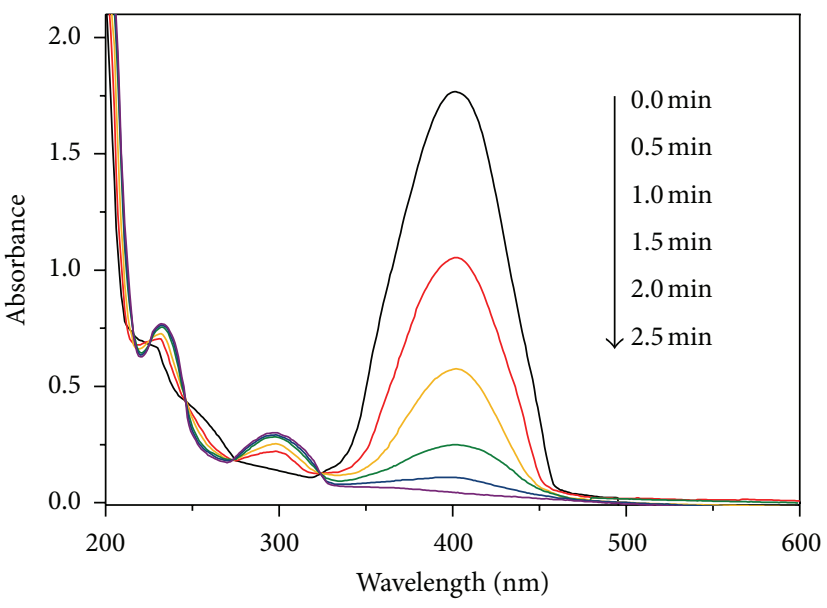

(b)

FIGURE 5: Hysteresis loop of Pt/Ni-G hybrids measured by SQUID magnetometer at $300 \mathrm{~K}$ (a). Successive UV-Vis spectra showing the reduction of $4-\mathrm{NP}$ catalyzed by $4.0 \mu \mathrm{g} \mathrm{Pt} / \mathrm{Ni}-\mathrm{G}$ hybrids (b).

317 to $400 \mathrm{~nm}$ occurred. This phenomenon was caused by the formation of $\mathrm{p}$-nitrophenolate ions in alkaline condition [38]. The intensity of the absorbance remained unchanged at $400 \mathrm{~nm}$ even after several days, indicating that no reduction of 4-NP occurred. However, in the presence of the Pt/Ni-G hybrids, quick reduction of 4-NP to p-aminophenol (4-AP) by $\mathrm{NaBH}_{4}$ was observed (Figure 5(b)). The absorption of 4-NP at $400 \mathrm{~nm}$ completely vanished within 2.5 minutes, accompanied by the fast appearance of the new peaks of 4-AP at $300 \mathrm{~nm}$ [39]. 
The excellent catalytic activity of the Pt/Ni-G hybrids can be attributed to the alloy nature of the supported $\mathrm{Pt} / \mathrm{Ni}$ nanoparticles, which usually show superior catalytic performance than their monometallic counterparts [40]. In addition, by dispersing on the two-dimensional graphene sheets with large surface areas, the $\mathrm{Pt} / \mathrm{Ni}$ nanoparticles can prevent aggregation that shields their active catalytic sites. Therefore, 4-NP molecules readily access the catalytic $\mathrm{Pt} / \mathrm{Ni}$ nanoparticles from two sides of the graphene sheets with limited mass transfer hindrance. Importantly, the $\mathrm{Pt} / \mathrm{Ni}-\mathrm{G}$ hybrids can be easily recycled by using an external magnetic field after the reaction and reused without observable decrease in their catalytic activities.

\section{Conclusions}

In summary, we developed a simple one-step route to prepare the graphene supported $\mathrm{Pt} / \mathrm{Ni}$ nanoparticles $(\mathrm{Pt} / \mathrm{Ni}-\mathrm{G})$. The supported $\mathrm{Pt} / \mathrm{Ni}$ nanoparticles had a mean diameter of $15 \mathrm{~nm}$ and showed superparamagnetic behavior. Catalytic investigation revealed the excellent catalytic activity of the obtained hybrids in the catalytic reduction of aromatic nitro compounds. Notably, the Pt/Ni-G hybrids could be easily separated from the reaction mixtures by applying an external magnetic field. Given their excellent catalytic performances, as well as their magnetically separable nature, these $\mathrm{Pt} / \mathrm{Ni}-\mathrm{G}$ hybrids are ideal recoverable nanocatalysts and may find potential applications in a variety of reactions.

\section{Acknowledgments}

This study was supported by the National Natural Science Funds for Excellent Young Scholars (no. 21222608), Research Fund of the National Natural Science Foundation of China (no. 21106099), Foundation for the Author of National Excellent Doctoral Dissertation of China (no. 201251), the Tianjin Natural Science Foundation (no. 11JCYBJC01700), and the Programme of Introducing Talents of Discipline to Universities (no. B06006).

\section{References}

[1] K. S. Novoselov, A. K. Geim, S. V. Morozov et al., "Electric field in atomically thin carbon films," Science, vol. 306, no. 5696, pp. 666-669, 2004.

[2] A. K. Geim and K. S. Novoselov, "The rise of graphene," Nature Materials, vol. 6, no. 3, pp. 183-191, 2007.

[3] M. H. Rümmeli, C. G. Rocha, F. Ortmann et al., "Graphene: piecing it together," Advanced Materials, vol. 23, no. 39, pp. 4471-4490, 2011.

[4] M. J. Allen, V. C. Tung, and R. B. Kaner, "Honeycomb carbon: a review of graphene," Chemical Reviews, vol. 110, no. 1, pp. 132$145,2010$.

[5] S. Stankovich, D. A. Dikin, G. H. B. Dommett et al., "Graphenebased composite materials," Nature, vol. 442, no. 7100, pp. 282286, 2006.

[6] Y. Li, X. Fan, J. Qi et al., "Palladium nanoparticle-graphene hybrids as active catalysts for the Suzuki reaction," Nano Research, vol. 3, no. 6, pp. 429-437, 2010.
[7] J. Wang, C. An, J. Liu et al., "Graphene oxide coupled AgBr nanosheets: an efficient dual-functional visible-light-responsive nanophotocatalyst with enhanced performance," Journal of Materials Chemistry A, vol. 1, no. 8, pp. 2827-2832, 2013.

[8] X. Cui, C. Zhang, R. Hao, and Y. Hou, "Liquid-phase exfoliation, functionalization and applications of graphene," Nanoscale, vol. 3, no. 5, pp. 2118-2126, 2011.

[9] T. Xue, S. Jiang, Y. Qu et al., "Graphene-supported hemin as a highly active biomimetic oxidation catalyst," Angewandte Chemie-International Edition, vol. 51, no. 16, pp. 3822-3825, 2012.

[10] Q. Zhao, D. Chen, Y. Li, G. Zhang, F. Zhang, and X. Fan, "Rhodium complex immobilized on graphene oxide as an efficient and recyclable catalyst for hydrogenation of cyclohexene," Nanoscale, vol. 5, no. 3, pp. 882-885, 2013.

[11] M. J. McAllister, J.-L. Li, D. H. Adamson et al., "Single sheet functionalized graphene by oxidation and thermal expansion of graphite," Chemistry of Materials, vol. 19, no. 18, pp. 4396-4404, 2007.

[12] D. A. Dikin, S. Stankovich, E. J. Zimney et al., "Preparation and characterization of graphene oxide paper," Nature, vol. 448, no. 7152, pp. 457-460, 2007.

[13] F. Scarpa, S. Adhikari, and A. Srikantha Phani, "Effective elastic mechanical properties of single layer graphene sheets," Nanotechnology, vol. 20, no. 6, Article ID 065709, 2009.

[14] T. Jin, S. Guo, J. 1. Zuo, and S. Sun, "Synthesis and assembly of $\mathrm{Pd}$ nanoparticles on graphene for enhanced electrooxidation of formic acid," Nanoscale, vol. 5, no. 1, pp. 160-163, 2013.

[15] T. Zeng, X. Zhang, Y. Ma, H. Niu, and Y. Cai, "A novel $\mathrm{Fe}_{3} \mathrm{O}_{4^{-}}$ graphene-Au multifunctional nanocomposite: green synthesis and catalytic application," Journal of Materials Chemistry, vol. 22, no. 35, pp. 18658-18663, 2012.

[16] P. Kundu, C. Nethravathi, P. A. Deshpande, M. Rajamathi, G. Madras, and N. Ravishankar, "Ultrafast microwave-assisted route to surfactant-free ultrafine Pt nanoparticles on graphene: synergistic co-reduction mechanism and high catalytic activity," Chemistry of Materials, vol. 23, no. 11, pp. 2772-2780, 2011.

[17] H. Chen, Y. Li, F. Zhang, G. Zhang, and X. Fan, "Graphene supported Au-Pd bimetallic nanoparticles with core-shell structures and superior peroxidase-like activities," Journal of Materials Chemistry, vol. 21, no. 44, pp. 17658-17661, 2011.

[18] S. Guo, D. Wen, Y. Zhai, S. Dong, and E. Wang, "Platinum nanoparticle ensemble-on-graphene hybrid nanosheet: onepot, rapid synthesis, and used as new electrode material for electrochemical sensing," ACS Nano, vol. 4, no. 7, pp. 3959-3968, 2010.

[19] D. Astruc, F. Lu, and J. R. Aranzaes, "Nanoparticles as recyclable catalysts: the frontier between homogeneous and heterogeneous catalysis," Angewandte Chemie-International Edition, vol. 44, no. 48, pp. 7852-7872, 2005.

[20] S. Shylesh, V. Schünemann, and W. R. Thiel, "Magnetically separable nanocatalysts: bridges between homogeneous and heterogeneous catalysis," Angewandte Chemie - International Edition, vol. 49, no. 20, pp. 3428-3459, 2010.

[21] S. Ceylan, C. Friese, C. Lammel, K. Mazac, and A. Kirschning, "Induktives heizen in der organischen synthese durch verwendung funktionalisierter magnetischer nanopartikel in mikroreaktoren," Angewandte Chemie, vol. 120, no. 46, pp. 9083-9086, 2008.

[22] Y. Chi, Q. Yuan, Y. Li et al., "Synthesis of $\mathrm{Fe}_{3} \mathrm{O}_{4} @ \mathrm{SiO}_{2}-\mathrm{Ag}$ magnetic nanocomposite based on small-sized and highly dispersed 
silver nanoparticles for catalytic reduction of 4-nitrophenol," Journal of Colloid and Interface Science, vol. 383, no. 1, pp. 96102, 2012.

[23] C. Kamonsatikul, T. Khamnaen, P. Phiriyawirut, S. Charoenchaidet, and E. Somsook, "Synergistic activities of magnetic iron-oxide nanoparticles and stabilizing ligands containing ferrocene moieties in selective oxidation of benzyl alcohol," Catalysis Communications, vol. 26, pp. 1-5, 2012.

[24] Y.-H. Liu, J. Deng, J.-W. Gao, and Z.-H. Zhang, “Triflic acidfunctionalized silica-coated magnetic nanoparticles as a magnetically separable catalyst for synthesis of gem-dihydroperoxides," Advanced Synthesis and Catalysis, vol. 354, no. 2-3, pp. 441-447, 2012.

[25] V. Polshettiwar and R. S. Varma, "Nanoparticle-supported and magnetically recoverable ruthenium hydroxide catalyst: efficient hydration of nitriles to amides in aqueous medium," Chemistry-A European Journal, vol. 15, no. 7, pp. 1582-1586, 2009.

[26] A. Lerf, H. He, M. Forster, and J. Klinowski, "Structure of graphite oxide revisited," The Journal of Physical Chemistry B, vol. 102, no. 23, pp. 4477-4482, 1998.

[27] S. Park and R. S. Ruoff, "Chemical methods for the production of graphenes," Nature Nanotechnology, vol. 4, no. 4, pp. 217-224, 2009.

[28] T. R. Mandlimath and B. Gopal, "Catalytic activity of first row transition metal oxides in the conversion of p-nitrophenol to paminophenol," Journal of Molecular Catalysis A, vol. 350, no. 1-2, pp. 9-15, 2011.

[29] F. Davar, Z. Fereshteh, and M. Salavati-Niasari, "Nanoparticles $\mathrm{Ni}$ and NiO: synthesis, characterization and magnetic properties," Journal of Alloys and Compounds, vol. 476, no. 1-2, pp. 797801, 2009.

[30] S. K. Singh and Q. Xu, "Bimetallic Ni-Pt nanocatalysts for selective decomposition of hydrazine in aqueous solution to hydrogen at room temperature for chemical hydrogen storage," Inorganic Chemistry, vol. 49, no. 13, pp. 6148-6152, 2010.

[31] H. Gao, F. Xiao, C. B. Ching, and H. Duan, "One-step electrochemical synthesis of PtNi nanoparticle-graphene nanocomposites for nonenzymatic amperometric glucose detection," ACS Applied Materials and Interfaces, vol. 3, no. 8, pp. 30493057, 2011.

[32] K. T. Ng and D. M. Hercules, "Studies of nickel-tungstenalumina catalysts by X-ray photoelectron spectroscopy," The Journal of Physical Chemistry, vol. 80, no. 19, pp. 2094-2102, 1976.

[33] R. Schulz, A. van Neste, P. A. Zielinski et al., "A novel method to produce nanocrystalline metastable supported catalysts," Catalysis Letters, vol. 35, no. 1-2, pp. 89-106, 1995.

[34] Y. Li, L. Tang, and J. Li, "Preparation and electrochemical performance for methanol oxidation of pt/graphene nanocomposites," Electrochemistry Communications, vol. 11, no. 4, pp. 846849, 2009.

[35] I. S. Lee, N. Lee, J. Park et al., "Ni/NiO core/shell nanoparticles for selective binding and magnetic separation of histidinetagged proteins," Journal of the American Chemical Society, vol. 128, no. 33, pp. 10658-10659, 2006.

[36] N. Amin, S. Arajs, and E. Matijevic, "Magnetic properties of submicronic $\alpha-\mathrm{Fe}_{2} \mathrm{O}_{3}$ particles of uniform size distribution at 300 K," Physica Status Solidi (A), vol. 104, no. 1, pp. K65-K68, 1987.
[37] T. Seto, H. Akinaga, F. Takano, K. Koga, T. Orii, and M. Hirasawa, "Magnetic properties of monodispersed $\mathrm{Ni} / \mathrm{NiO}$ coreshell nanoparticles," The Journal of Physical Chemistry B, vol. 109, no. 28, pp. 13403-13405, 2005.

[38] N. Pradhan, A. Pal, and T. Pal, "Silver nanoparticle catalyzed reduction of aromatic nitro compounds," Colloids and Surfaces A, vol. 196, no. 2-3, pp. 247-257, 2002.

[39] J. Huang, S. Vongehr, S. Tang, H. Lu, and X. Meng, "Highly catalytic Pd-Ag bimetallic dendrites," The Journal of Physical Chemistry C, vol. 114, no. 35, pp. 15005-15010, 2010.

[40] H.-L. Jiang and Q. Xu, "Recent progress in synergistic catalysis over heterometallic nanoparticles," Journal of Materials Chemistry, vol. 21, no. 36, pp. 13705-13725, 2011. 

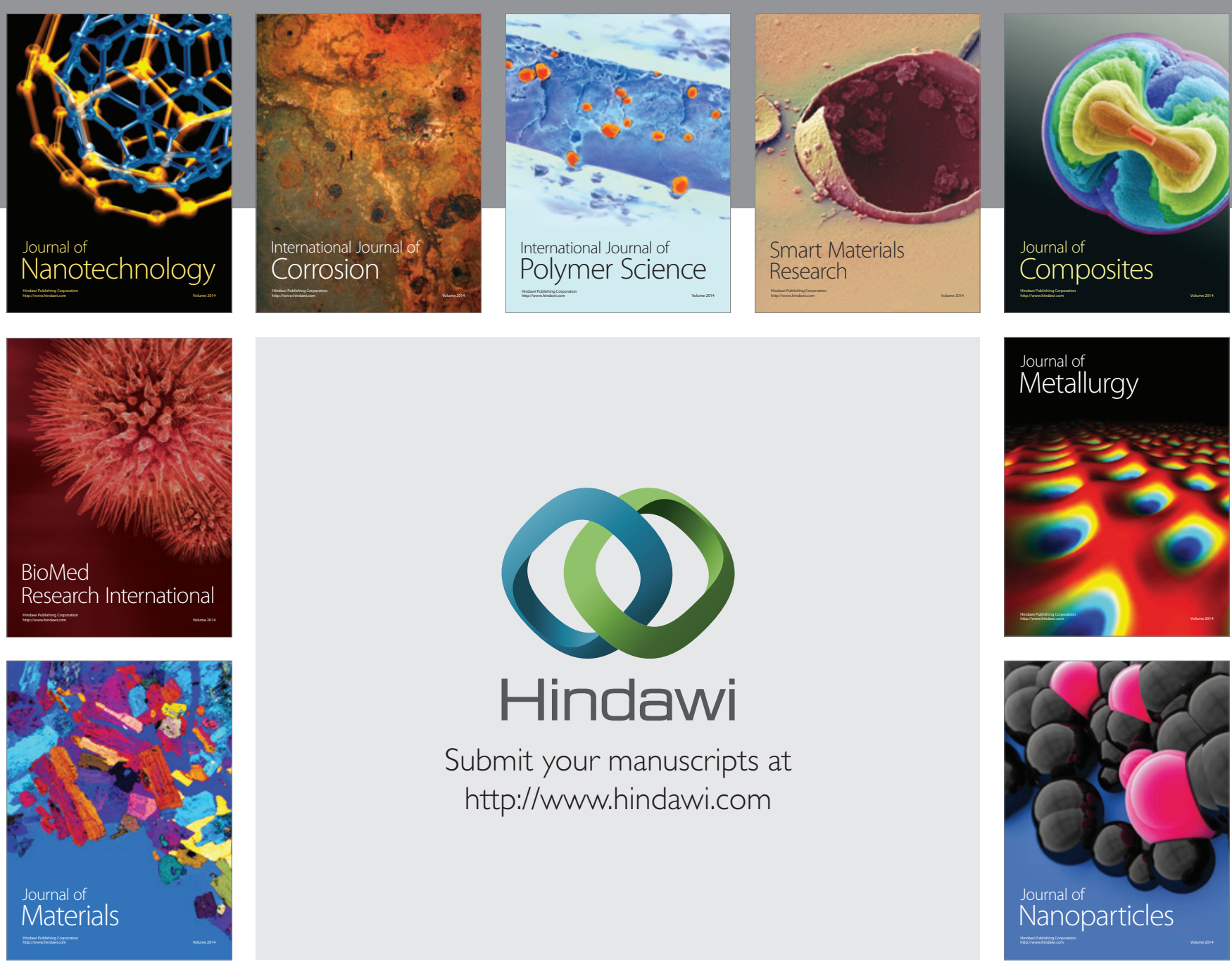

Submit your manuscripts at http://www.hindawi.com
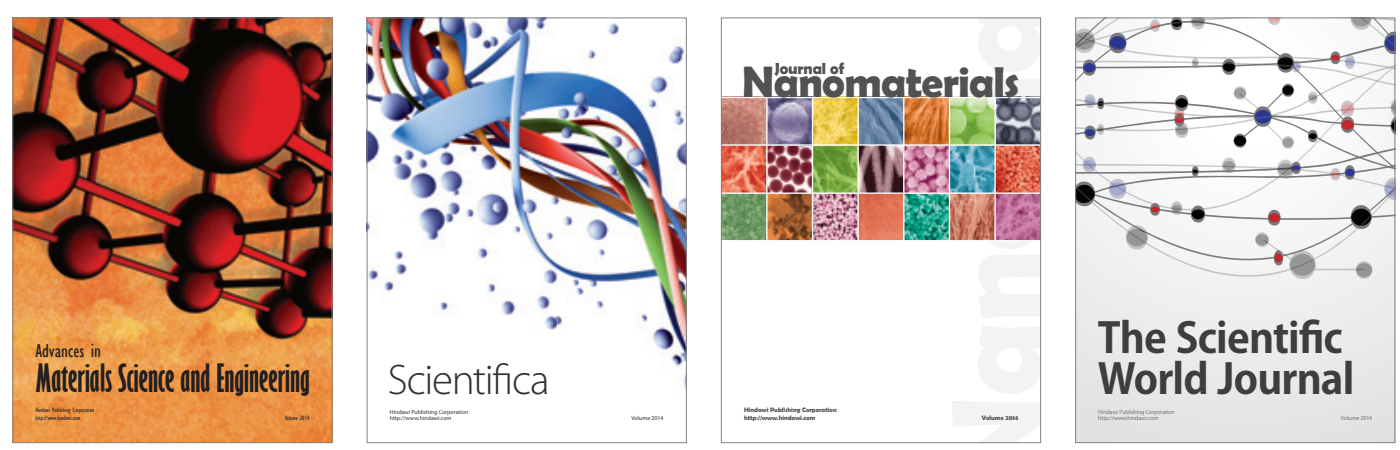

\section{The Scientific World Journal}
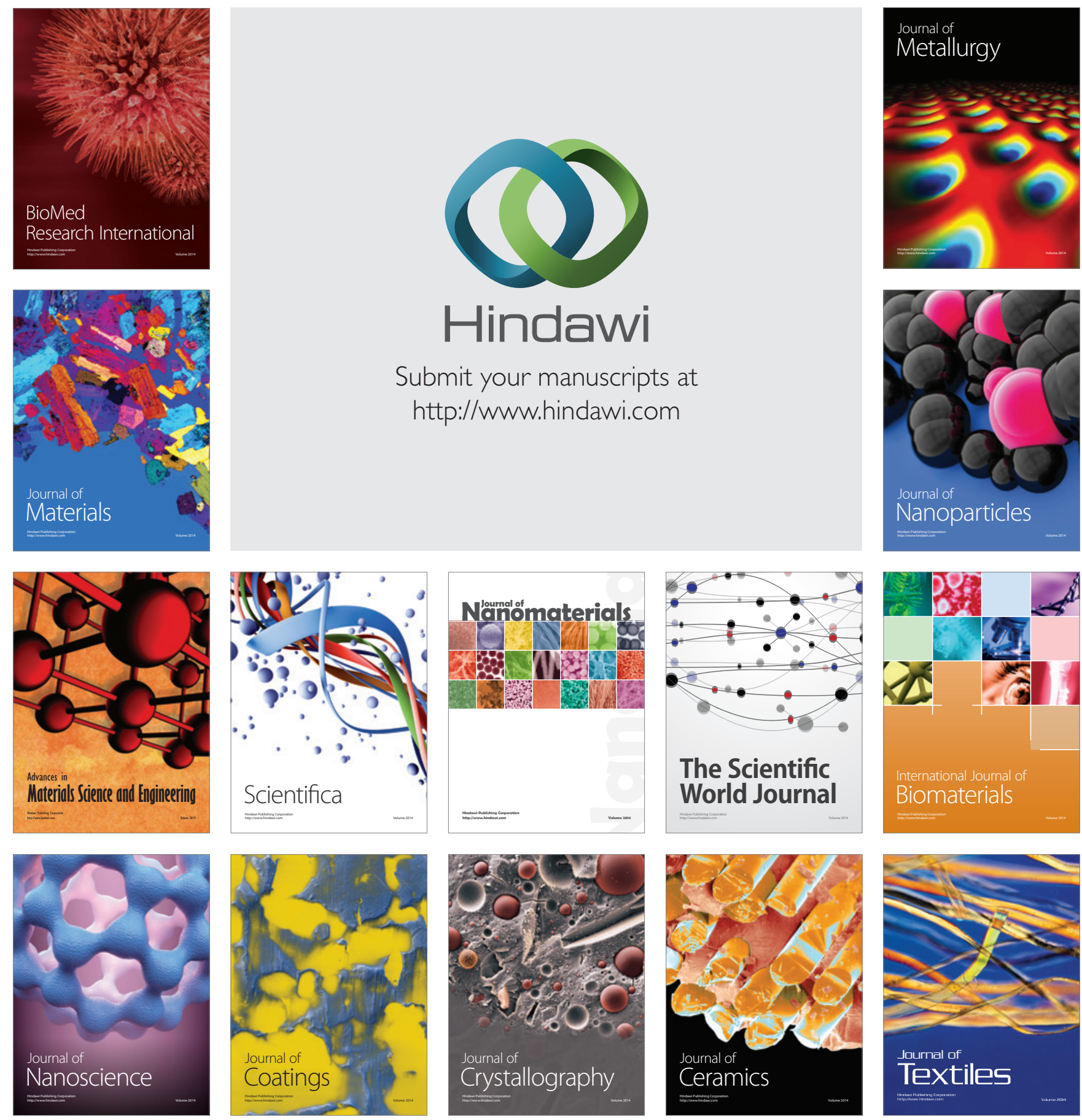